\title{
The Relationship Between Core Stability \& Squat Ratio in Resistance-Trained Males
}

\author{
Tyler Ray \\ Department of Kinesiology and Recreation, Southern Utah University \\ 351 West University Blvd, Cedar City, Utah 84720, Utah, USA \\ E-mail: rayt@mail.gvsu.edu \\ Kent J. Adams \\ Kinesiology Department, California State University Monterey Bay \\ 100 Campus Center, Seaside, California 93955, USA \\ E-mail: Kent_Adams@csumb.edu \\ Mark DeBeliso (Corresponding author) \\ Department of Kinesiology and Recreation, Southern Utah University \\ 351 West University Blvd, Cedar City, Utah 84720, USA \\ E-mail:markdebeliso@suu.edu
}

Received: 11-02- 2017

Accepted: 08-04- 2017

Published: 30-04- 2017

doi:10.7575/aiac.ijkss.v.1n.1p.7

URL: http://dx.doi.org/10.7575/aiac.ijkss.v.2n.1p.7

\begin{abstract}
Background: The lumbopelvic-hip complex, also referred to as the "core", is composed of every muscle between the knees and sternum. The back squat (BS) and front squat (FS) are both staple exercises that challenge the core in different ways. Possessing a properly balanced squat ratio (SR = 1-RM FS/1-RM BS; 1-RM = one-repetition maximum) could lead to a more stable core. Objective: This study attempted to determine if there was a meaningful relationship between the SR and core strength (CS) in resistance-trained males. If a strong relation exists between the SR and CS, strength and conditioning professionals would have a readily available assessment tool for examining CS by simply viewing the SR. Method: Twenty-one resistance-trained males (age $=28.3 \pm 6.2$ years; body mass $=93.1 \pm 13.1 \mathrm{~kg}$; height $=181.9 \pm 7.6 \mathrm{~cm}$; weight training experience with FS \& BS $=6.4 \pm 3.7$ years) performed CS tests (flexor endurance, extensor endurance, prone bridge, left side-bridge, and right side-bridge), along with a 1-RM in the BS and FS. An aggregate of the CS test times (CSA) was also calculated for comparison with the SR. A Pearson productmoment correlation coefficient $(r)$ was used to compare the SR with the CS tests and the CSA. Results: The CS test results were as follows (secs): flexor endurance $228.2 \pm 93.0$, extensor endurance $137.0 \pm 28.2$, prone bridge $166.7 \pm 51.3$, left side-bridge 97.36 \pm 31.0 , right side-bridge 100.2 \pm 28.3 , and CSA 729.8 \pm 165.4 . The 1-RM BS, 1-RM FS, and SR were: $157.5 \pm 29.7 \mathrm{kgs}, 132.2 \pm 24.3 \mathrm{kgs}$, and $0.84 \pm 0.06$ respectively. A moderate correlation was found between total CSA and the $\mathrm{SR}\left(\mathrm{r}=0.50, \mathrm{CD}^{2}=0.25, \mathrm{p}<0.05\right)$. In addition, a moderate correlation was found between the prone bridge test and the $\mathrm{SR}\left(\mathrm{r}=0.49, \mathrm{CD}^{2}=0.24, \mathrm{p}<0.05\right)$. A very strong positive correlation was also found between $1-\mathrm{RM}$ BS and 1-RM FS $\left(r=0.93, C D^{2}=0.86, p<0.05\right)$. Conclusions: The results of this study suggest that the CSA and prone bridge test are moderately related to the SR. However, the low coefficient of determination between the SR and CS times suggests that the SR is not a suitable estimate of CS. The very strong relationship between the 1-RM FS and 1RM BS provides strong evidence for the interchangeable use of these modalities within a resistance training protocol.
\end{abstract}

Keywords: Front Squat, Back Squat, Core Strength.

\section{Introduction}

The back squat (BS) and front squat (FS) are primary, multi-joint exercises key to the development of muscular strength, power, and athletic performance. Both variations strengthen muscles around the knees and hips, and enhance the balance and stability of the core (Comfort et al., 2011; Contreras et al., 2016) by eliciting isometric contractions of the core muscles to keep the torso upright and provide a neutral spine during performance (Hamlyn et al., 2007). The core muscles of the body used when squatting are essentially every muscle between the knees and sternum; these muscles are often referred to as the lumbopelvic-hip complex, which include the diaphragm, latissimus dorsi, the abdominal wall (i.e., rectus abdominis, transversus abdominis, external obliques, and internal obliques), the pelvic floor (i.e., piriformis, levator ani, and coccygeus), the paraspinals (i.e., erector spinae, multifidus, rotatores, and seminspinals), the hip girdle (i.e., hamstrings, rectus femoris, gluteus maximus, gluteus medius, gluteus minimus, psoas major and minor), and the quadratus lumborum (Huxel-Bliven \& Anderson, 2013; Kibler et al., 2006). In order for an individual to perform either squat variation optimally, they must possess the proper core stability (CS) needed to maintain lumbar stability throughout the descent and ascent phase. When athletes perform the squat and do not maintain a neutral or slightly 
extended spinal position, an increase of shear and compressive forces could force the spine to buckle (DeBeliso et al., 2013; Walsh et al., 2007), potentially causing serious injuries. There is limited research comparing the electromyography (EMG) activity between the FS and BS; however, in relation to the core musculature, studies do demonstrate significant differences between the two squat variations. Yavuz et al., 2015 showed that knee extensors (i.e., vastus medialis and vastus lateralis) EMG activity is higher in the FS, while hamstring (i.e., semitendinosus) EMG activity is higher in the BS. The BS also places a greater amount of net compressive forces on the knee as opposed to the FS (Gullet et al., 2009) and the BS generates more force from the hips, while the FS produces a greater amount of force from the knees (Braidot et al., 2007). Regarding trunk activity while squatting with $70 \%$ of 1-RM, Raizanda \& Bagchi (2015) found a slightly higher activation of the paraspinal muscles in the FS than in the BS; and Comfort et al. (2011) found that the FS challenges the erector spinae muscles to a slightly greater extent than the BS does, however no significant difference was found in rectus abdominis EMG activity between the squat variations. From a practical standpoint, these subtle differences highlight the importance of including variation in a given exercise in order to optimize overall adaptation of specific muscle groups that function together such as the core. Considering that the primary role of the core in daily life is to maintain postural stability over a period of time, several researchers suggest that isometric core endurance tests should be used to test CS (Cowley \& Swensen, 2008; Wilson et al., 2005; McGill et al., 1999). While meaningful, this test battery requires additional time and expertise over the commonly performed 1RM squat test, and may not be as specific to the acute, explosive nature of many athletic events, whereas the squat is related to the athletic performance variables of vertical jumping and sprint speed (Wisløff, et al., 2004). If a strong association exists between the squat ratio-SR (1-RM FS/1-RM BS) and CS, strength and conditioning professionals would have a readily available assessment tool for examining core strength by simply viewing the SR, saving the time necessary to assess CS with traditional endurance-based tests. To our knowledge, there has been no research conducted examining the relationship between CS and BS and FS 1-RM. Therefore, the purpose of this study was to examine the relationship between the SR and CS in males. It was hypothesized that participants CS scores will be strongly correlated with their SR.

\section{Methods}

\subsection{Experimental Approach to the Problem}

Previous research suggests that the FS and BS are strongly correlated to one another (Comfort et al., 2011; Gullet et al., 2009; Raizanda \& Bagchi, 2015; Yavuz et al., 2015), although there is no previous research to suggest a relationship between core stability (CS) and both squat variations (i.e., FS and BS). The current study attempted to analyze the correlation between the squat ratio (1-RM FS/1-RM BS) and CS tests in resistance trained males to evaluate if an individual's squat ratio (SR) is associated CS test scores. To do so, a Pearson product-moment correlation coefficient $(r)$ was used for this study. Measurements of CS included (Figure 1): flexor endurance test, extensor endurance test, prone bridge test, left side-bridge test, and right side-bridge test. Also, an aggregate CS score was calculated as the sum of all of the CS measures in seconds (CSA). Both squat variations were also assessed (Figure 2): 1-RM BS and 1-RM FS.

\subsection{Participants}

Participants were 21 resistance-trained males (age $=28.3 \pm 6.2$ years; body mass $=93.1 \pm 13.1 \mathrm{~kg}$; height $=181.9 \pm 7.6$ $\mathrm{cm}$ ); with $6.4 \pm 3.7$ years of resistance training experience in the FS and BS. Inclusion criteria for subjects was $\geq 18$ years of age, have $\geq$ one year of consistent resistance training experience using both the FS and BS, the ability to hold the front rack position in a FS, and be injury/disability free that would prevent them from participating in the testing protocols in a manner similar to that discussed by Shariat and colleagues (2015). Participants were volunteers from Crossfit Luminary with no financial compensation provided. This study was approved by the Southern Utah University Institutional Review Board and all participants gave written consent before data collection.

\subsection{Procedures}

Participants reported for a total of three testing sessions, separated by one week and each session lasted about 45-60 minutes in duration. All testing sessions were held at Crossfit Luminary in Grand Rapids, MI. During the first session, age, height, mass, and the 1-RM BS were assessed. The second session (one week later) included the 1-RM FS, while CS tests were completed during the third session (see Figure 3). Before testing each day, participants performed a general dynamic warm-up for 5-10 minutes that included rowing and calisthenics (i.e. leg swings, bodyweight squats, lunges, push-ups, etc.). Participants were encouraged to maintain their typical diet and refrain from working out 48 hours prior to each testing session. However diet and supplement usage (legal or illegal) could not be verifiably controlled. 

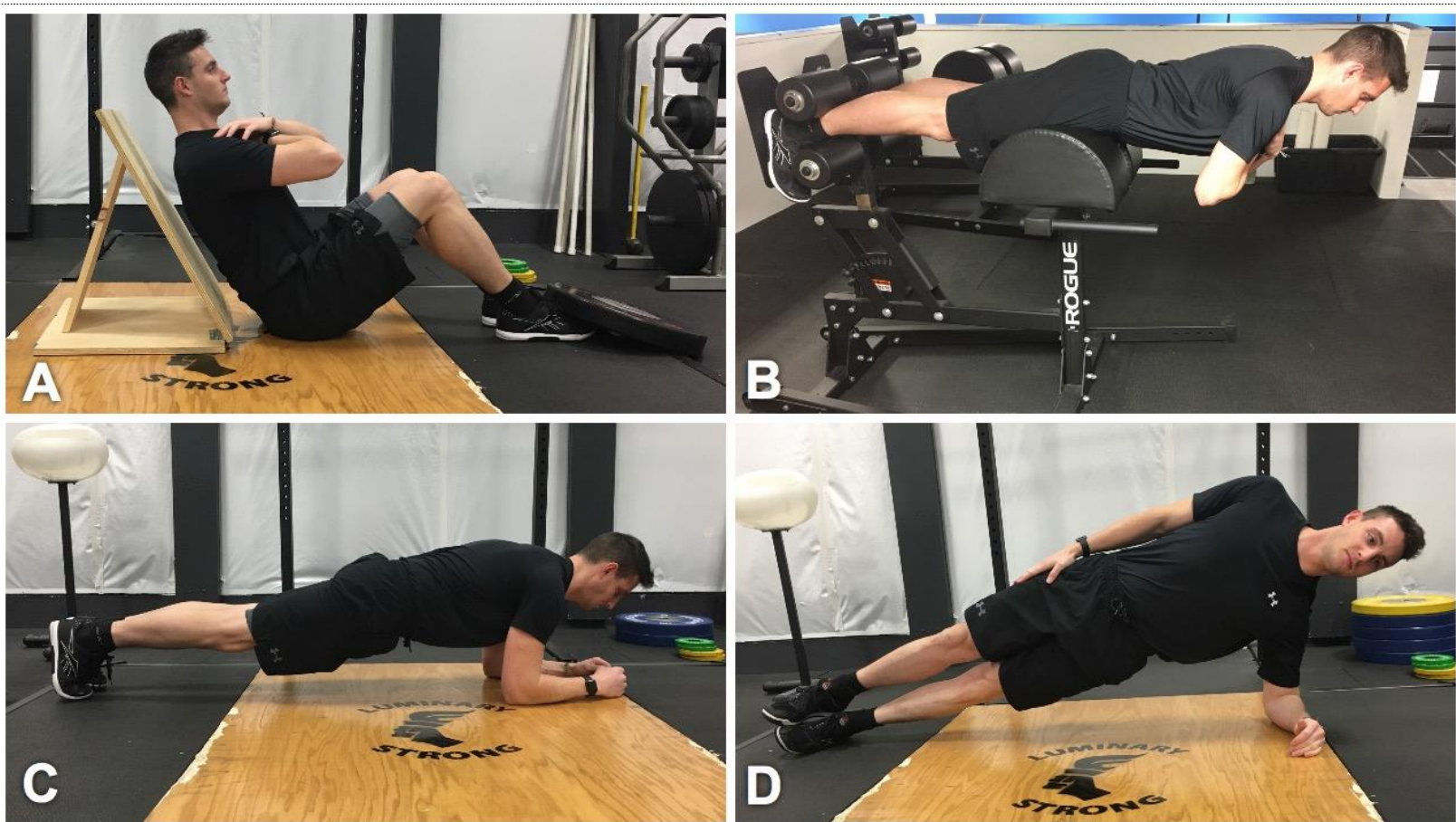

Figure 1. Tests used for assessment of core stability. A) Flexor endurance. B) Extensor endurance. C) Prone bridge. D) Side-bridge.
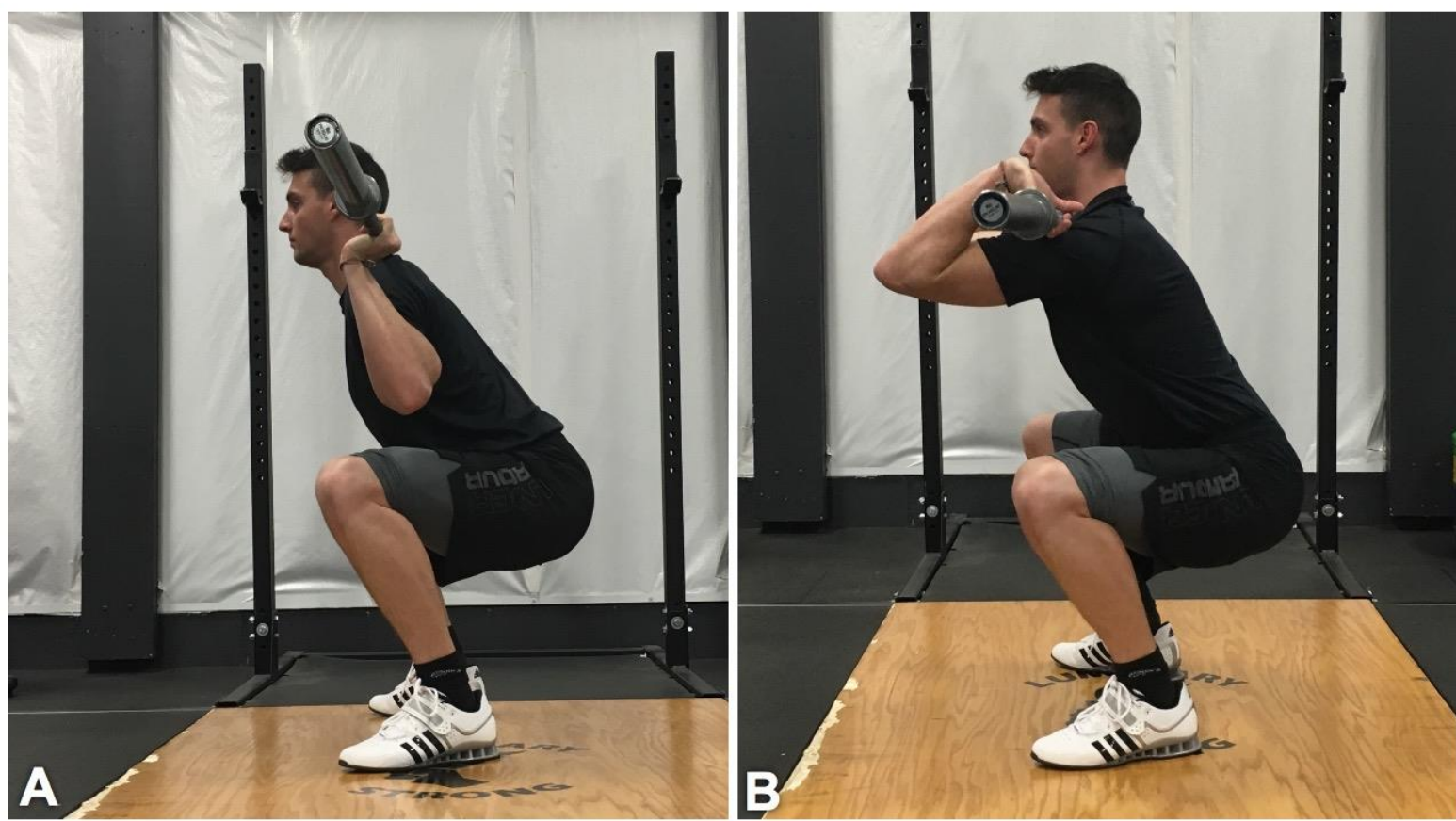

Figure 2. One-repetition maximum squat variations. A) Back squat. B) Front squat.

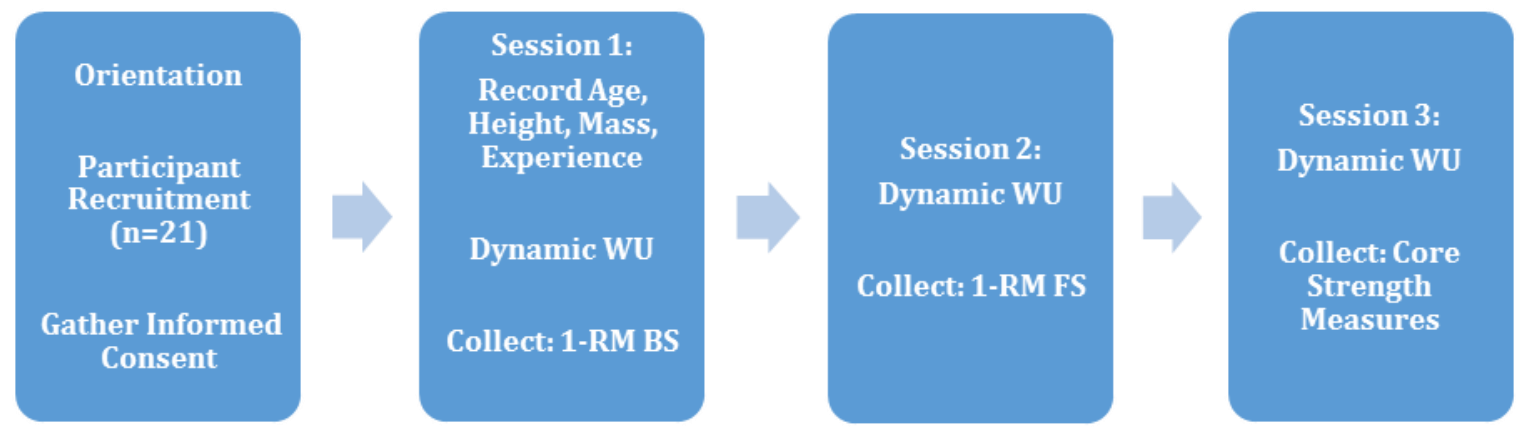

Figure 3. Study time line overview of events (WU-warm-up; 1-RM-one repetition maximum; BS-back squat; FS-front squat). 


\subsection{Squat Ratio (SR) Measurements}

The first two sessions were composed of the 1-RM for the FS and BS. To begin the first session, participants performed a dynamic warm-up. After the dynamic warm-up, participants rested for 5 minutes then performed the BS 1-RM protocol as recommended by the National Strength \& Conditioning Association (NSCA) (Baechle \& Earle, 2008, p. 396). Participants' started by performing an attempt at $50 \%$ of a recent or projected $1-\mathrm{RM}$ and the weight was increased in increments of 10-20 kg until their 1-RM was achieved. The 1-RM measures were recorded within 5 sets. To maintain validity, participant's technique was monitored closely. For a successful 1-RM to be counted, the participant needed to perform the squat with proper form by reaching parallel and maintaining a neutral spine. Test-retest reliability of between 0.92 and 0.99 were reported for 1-RM BS (McBride et al. 2002; Sanborn et al. 2000). In addition, the reliability of the squat has been reported as ICC=0.91-0.99 (McMaster et al., 2014; Seo et al., 2012). One week later in session two, participants performed the dynamic warm-up as described above and then performed the same NSCA 1RM protocol for the FS (Baechle \& Earle, 2008, p. 396). The only difference between the two tests is that the BS required participants to position the barbell behind the neck on the posterior deltoids (high bar position); in comparison, the FS had participants position the bar in front of the neck on the top of the clavicle with the shoulders pinning the bar against the body (see Figure 2). All measurements were assessed by a NSCA certified strength and conditioning specialist (CSCS). An Olympic style weight bar $(20.45 \mathrm{~kg})$ along with weighted plates was used to assess the 1-RM BS and FS.

\subsection{Core Stability Testing}

During session three, the core test battery of McGill (McGill, 1998; McGill et al., 1999) was used to assess muscular endurance of the torso stabilizer muscles. The following tests (i.e., left side-bridge, right side-bridge, extensor endurance, prone bridge, and flexor endurance) were administered at random with each test being performed once. A digital handheld stopwatch was used to assess the duration of time participants were able to maintain the isometric positions. Participants were allowed up to 5 minutes of rest between each test. The reliability of the CS tests has been reported: flexor endurance test (ICC=0.98), Biering-Sorensen isometric extensor test (ICC=0.93), and left and rightbridge test (ICC=0.95) (Nesser et al., 2008). In addition, the prone bridge has shown to have a reliability of ICC $=0.95$ in healthy adults (Durall et al., 2012).

\subsubsection{Extensor Endurance Test}

This test was modified from the Biering-Sorensen test (McGill et al. 1999) by using a glute ham developer. The subject lay prone on a glute ham developer with their feet anchored and the center of their hips directly over the pad. Arms were crossed over the chest. The subject was instructed to achieve a position parallel to the testing surface and hold this for as long as possible. Time was stopped when the subjects' trunk sloped downward by more than 5-10 degrees.

\subsubsection{Flexor Endurance Test}

The subject leaned against a wedge at a 60 -degree angle with their feet pinned down by a $20 \mathrm{~kg}(45 \mathrm{lbs})$ weighted plate, while the knees and hips were bent at 90 degrees. Arms were crossed over the chest. The wedge was then pulled back $10 \mathrm{~cm}$ and the subject had to maintain the position as long as possible. The position was considered not being maintained when the subject touched the wedge again.

\subsubsection{Prone Bridge Test}

The subject started in the prone position the elbows in contact with the floor and supporting the torso. The elbows were placed shoulder-width apart and the feet were close together but not in contact. The participant lifted the pelvis from the floor leaving only the forearms and toes in contact with the floor. The upper torso was held isometrically in line with the hips and ankles. Time was stopped once the subject lowered their hips more than 5-10 degrees.

\subsubsection{Side-Bridge Test}

The side-bridge was performed once on each side. The subject laid on their side with the feet arranged together in a stacked fashion and then were directed to lift their hips upward and off the ground and try to achieve a straight line over the length of the body. A straight line was determined by the tester. The subject supported themselves on the bottom elbow and the feet. The unengaged arm was laid alongside of the body. Time was stopped when the subject broke the straight line.

\subsection{Statistical Analysis}

A Pearson product-moment correlation coefficient $(r)$ was used to evaluate relationships between the SR and the following test variables: aggregate CS scores (CSA); flexor endurance; extensor endurance; prone bridge; left sidebridge; and right side-bridge. Another Pearson correlation coefficient $(r)$ was used between the 1-RM BS and the 1-RM FS to determine the strength of the relationship. The SR was calculated by dividing the 1-RM FS by the 1-RM BS results. Statistical significance was set at alpha $\leq 0.05$. Statistical analysis was conducted with Microsoft Excel software (2015).

\section{Results}

Core test and the squat 1-RM scores are listed in Table 1. There was a moderate positive correlation between CSA test times and the SR $(\mathrm{r}=0.50: p \leq 0.05)$. There was also a moderate positive correlations between the prone bridge test and the SR $(\mathrm{r}=0.49: p \leq 0.05)$ as well as the left bridge test and the SR $(\mathrm{r}=0.41: p \leq 0.05)$. However, no other correlations 
were significant. The SR and CS correlations are given in Table 2. Also noteworthy, there was a very strong positive correlation between the 1-RM BS and 1-RM FS $(\mathrm{r}=0.93$ : $p \leq 0.05)$.

Table 1. Core and performance variables (mean $\pm \mathrm{SD}$ )

\begin{tabular}{lr}
\hline 1-RM BS (kg) & $157.5 \pm 29.7$ \\
1-RM FS (kg) & $132.2 \pm 24.3$ \\
1-RM BS/BM & $1.7 \pm 0.3$ \\
1-RM FS/BM & $1.4 \pm 0.3$ \\
Squat ratio & $0.84 \pm 0.06$ \\
Flexor endurance test (secs) & $228.2 \pm 93.0$ \\
Extensor endurance test (secs) & $137.0 \pm 28.2$ \\
Prone bridge test (secs) & $166.7 \pm 51.3$ \\
Left side-bridge test (secs) & $97.6 \pm 31.0$ \\
Right side-bridge test (secs) & $100.2 \pm 28.3$ \\
CSA (secs) & $729.8 \pm 165.4$ \\
\hline 1-RM: one-repetition maximum, BS: back squat, FS: front squat, BM: body mass, CSA: aggregate \\
of CS scores & \\
Table 2. Squat ratio and core stability test correlations (r) & \\
\hline Core Stability Test & Squat Ratio \\
\hline CSA & $0.50 *$ \\
Flexor endurance test & 0.32 \\
Extensor endurance test & 0.17 \\
Prone bridge test & $0.49 *$ \\
Left side-bridge test & $0.41^{*}$ \\
Right side-bridge test & 0.35 \\
\hline
\end{tabular}

$*$ Significant $(p \leq 0.05)$

\section{Discussion}

This study examined the relationship between the SR (i.e., 1-RM FS/1-RM BS) and CS in resistance-trained males. The study was attempting to provide a CS assessment tool for strength and conditioning coaches by simply comparing an individual's 1-RM FS to their 1-RM BS. We hypothesized that a participant's total of CS scores or an aggregate CS score (CSA) would strongly correlate with their SR. Results of the study indicate a moderate positive relationship between CSA and the SR. Correlations between the CS measures (flexor endurance test, extensor endurance test, left side-bridge test, right side-bridge test) and SR ranged from 0.17-0.41. The left side-bridge test and the right side-bridge test correlations to the SR were 0.41 and 0.35 respectively. The right side bride test correlation was slightly lower and we suspect this is due to general right arm dominance that may allow for a slightly stronger stabilization of the trunk during the test as opposed to the non-dominant arm. The right side bride test scores $(100.2 \pm 28.3$ secs $)$ were slightly higher than the left side bride test scores $(97.6 \pm 31.0 \mathrm{secs})$, although not significantly different $(\mathrm{p}=0.25)$. With that said, the correlations for the flexor endurance test, extensor endurance test, left side-bridge test, right side-bridge test and SR were so low that individually they provide little evidence supporting the notion of a meaningful relationship between $\mathrm{CS}$ and the SR. The prone bridge was the only individual CS measure to meaningful correlate with the SR $(r=0.49)$. The prone bridge was added to the CS test battery to further assess the extensor contribution of the pelvis and hips beyond what the extensor endurance test does. The prone bridge primarily assesses muscles such as the rectus abdominis, erector spinae, external oblique, and gluteus medius (Huxel-Bliven \& Anderson, 2013). It could also be argued that the prone bridge uses scapula stabilizing muscles that help retract and protract the scapula (Paine \& Voight, 2013). These scapula stabilizing muscles are very important when performing the FS, thereby helping participants lift more weight as compared to their BS. In this case, the strength of the musculature that contributes to a greater prone bridge time may likewise contribute to a greater SR. With that said, the other CS tests (flexor endurance test, extensor endurance test, left side-bridge test, right side-bridge test) were still of value from a collective stand point, as the CSA was moderately correlated to the SR. The moderate relationship between the SR and the CSA suggests that having longer CSA test time is related to having a higher SR. Conversely, a high SR is related to a greater score as assessed by the CSA. Hypothetically, focusing on the strengthening of the core musculature could lead to an improved SR. However, the effort of targeting core musculature would likely be only marginally effective at improving the SR. Specifically, as previously stated the correlation between the CSA and the SR was $r=0.50$ with a coefficient of determination $\left(\mathrm{CD}=\mathrm{r}^{2}\right) \mathrm{CD}=0.25$ which would indicate that $25 \%$ of the CSA and SR come from common factors (Safrit and Wood, 1995). To that end, a previous study by Tse et al. (2005) focused on performing targeted core training 
exercises in collegiate rowers. Results demonstrated an improvement in the participant's McGill CS tests scores, however there was no significant improvement in any of the performance variables tested (vertical and standing long jump, 40-m sprint, shuttle run, medicine ball toss, and rowing ergometer test). Conversely, a study by Sadeghi and colleagues (2013) focused on strengthening the core musculature in order to improve dynamic balance as measured by the Star excursion balance test. The results of their study demonstrated that focused core stabilization-training could improve dynamic balance of experienced college aged male volleyball players. Generally speaking the findings of the current study are consistent with two previous research studies by Nesser and colleagues (Nesser et al. 2008; Nesser and Lee, 2009). The initial study used the McGill CS tests (McGill et al. 1999) to examine the relationship between CS and performance variables in NCAA Division I North American football players. Similar to the current study, correlations ranged from weak to moderate. The follow up study by Nesser and Lee (2009) examined the relationship between CS and performance variables in NCAA Division I female soccer players and had similar findings. Results demonstrated no significant relationship between CS and any of the performance variables assessed (i.e., sprints, shuttle run, countermovement jump, BS and bench press). Based on the results of their two studies Nesser and colleagues suggest that the lack of meaningful correlations between the performance variables and CS was likely due to the tests being used to measure CS were not specific to athletic performance and strength, and/or CS does not play an integral role in athletic performance (Nesser et al. 2008; Nesser and Lee, 2009). We agree with the conclusions reached by Nesser and colleagues regarding the weak-moderate correlations between CS and performance measures, however our study focused on a performance ratio (SR) that we felt may be indicative of CS. The notion that the CS tests used in the current study as well as the Nesser and colleagues studies were not specific enough to the performance variables assessed was demonstrated by Nikolenko et al. (2011) in an attempt to determine the association between measures of sports performance and core power. They demonstrated a significant, but moderate correlation $(r=0.65)$ between the 1 RM BS and one of the dynamic core power tests used (i.e., front abdominal power throw). In the current study the CS tests were isometric muscular endurance based tests that ranged on average from 97.6-228.2 secs depending on the CS test. Whereas, the front abdominal throw test used in the Nikolenko study was a muscular power output test that required a very high force output over a brief short muscular exertion period (muscular power). Hence, the differing tests to assess CS in the current study and the Nikolenko study recruited different muscle fiber types and energy systems. The 1-RM BS and 1-RM FS scores in the current study were $157.5 \pm 29.7 \mathrm{~kg}$ and $132.2 \pm 24.3 \mathrm{~kg}$ respectively. When normalized to body mass the 1-RM BS/body mass and 1-RM FS/body mass scores were $1.7 \pm 0.3$ and $1.4 \pm 0.3$ respectively. There was a very strong positive correlation between the 1-RM FS \& 1-RM BS $(\mathrm{r}=0.93: p \leq 0.05)$. Previous research has also documented the strong relationship between the 1-RM FS \& 1-RM BS (Comfort et al., 2011; Gullet et al., 2009; Raizanda \& Bagchi, 2015; Yavuz et al., 2015). In the current study, the coefficient of determination between the 1-RM FS \& 1 -RM BS was $\left(C D=r^{2}\right) C D=0.86$ which would indicate that $86 \%$ of the 1 -RM FS \& $1-R M B S$ come from common factors (Safrit and Wood, 1995). This relation seems to validate the use of either the FS or BS as a measurement to test or train strength of the lower body. The mean SR in the current study was $0.84 \pm 0.1$ indicating that the 1-RM FS was $84 \%$ of the 1-RM BS. Similar results have been documented in a previous research by Yavuz et al. (2015) in a sample of healthy male adults. The mean 1-RM BS and 1-RM FS were $109.2 \pm 25.5 \mathrm{~kg}$ and $85.0 \pm 15.7 \mathrm{~kg}$ respectively. Hence the SR was 0.78 indicating that the 1-RM FS was $78 \%$ of the 1-RM BS. The slightly lower SR in the Yavuz et al. (2015) study could be due to the sample population used in their study that appeared to have less resistance training experience then the participants in the current study. As with any research of human performance, there are multiple limitations associated with this study. First, participants may not have been at maximal strength on days of testing; therefore, 1-RM squat variation amounts may differ depending on the state of fatigue, albeit we attempted to control that extraneous variable with clear instructions on rest. Second, participant's resistance training experience using the FS and BS ranged from 1-15 years with an age range 19-42 years old. As such, some participants had far more resistance training experience than others and could have performed each squat variation with better technique (e.g., greater/lesser trunk inclination, lower squat depth, optimal front rack position). Likewise, some athletes may have had different experience with training the core musculature and history with the BS as compared to the FS potentially impacting the mean score for the SR and CSA. Third, this study used McGill's CS tests with a few slight modifications (i.e., a prone bridge was added and a glute ham developer was used for the extensor endurance test). Fourth, the McGill CS tests and the prone bridge were developed to assess endurance of the core musculature when performing an extended isometric muscle contraction. However, these tests may not reflect how core muscles function under maximal loads when performing dynamic movements (i.e., 1-RM FS and 1-RM BS). The 1-RM squat variations required fast-twitch muscle fibers to contract with a maximum force production, while the CS tests were considered to be focused more on slow-twitch muscle fibers and submaximal contractions (Nesser et al., 2008). In addition, time to exhaustion in the CS endurance tests may be confounded by mental fatigue as opposed to just muscular endurance (Wilson et al., 2005).

\section{Practical Applications}

To our knowledge this is the first study to determine if there is a meaningful relationship between the SR and CS. This study found that there are moderate correlations between some of the CS test times (including the CSA) and the SR. Hence, the SR cannot be assumed to be a meaningful measure of CS. When attempting to assess an individual's CS, a battery of core strength tests should still be used as recommended by McGill (1999). Based on the results of this study, and in agreement with Nesser et al. (2009), we do not recommend that a strength and conditioning coach places inordinate training time on targeting the core musculature with the hopes of improving performance; and knowing that the FS and BS challenge the core musculature in a functional manner, it may not be necessary to designate specific 
additional training time and exercises for the development of the core musculature. A very strong correlation was found in the current study between the 1-RM FS and 1-RM BS. Our results support the notion that FS's and BS's are reasonably interchangeable modalities for the strength and conditioning coach to implement when the goal is to strengthen the lower body. Previous research also demonstrates that performing both squat variations will provide a sufficient stimulus to the core muscles (Comfort et al., 2011; Hamlyn et al., 2007; Yavuz et al., 2015). The FS has shown to decrease trunk inclination, which places the body in a more upright posture. In addition, the FS has proved to be equally effective as the BS in regards to muscle activity, with a significantly lower amount of compressive forces placed on the low back and knee (Yavuz et al., 2015). If athletes suffer from previous lumbar or knee injuries, or even want to strengthen the erector spinae to a greater extent, the FS could be used as opposed to the BS. Under maximal loads the BS allows athletes to lift a greater amount of weight, thus creating a greater stimulus on the hamstrings and hips. However, some athletes cannot hold the bar with proper shoulder positioning in the BS under higher training loads. When this occurs, a FS, which uses a front rack position may be an alternative in order to keep the shoulder in a more neutral and less externally rotated position (Fees et al., 1998). However, the front rack position in FS may be difficult for those who do not possess the necessary amount of flexibility and mobility of the wrist, elbow, and shoulder (see Figure 2 B). With that said, making the effort to learn the front rack position of the FS will ultimately be beneficial, as many variations of the Olympic lifts require a front racking position when coupling with the weight bar. While there are a host of benefits related to performing the FS, the BS is considered by some as having the greatest potential for increasing performance as greater loads can typically be lifted while performing the BS (O'Shea, 2000). In conclusion, both the FS and BS are primary exercises in a strength and power training program that also directly stress the core musculature. Understanding the specific nuances of the BS and FS provides strength and conditioning professionals with the flexibility of choice between the squat variation based on the individual's needs (or limitations) thereby helping to optimize the individualized resistance training program.

\section{Acknowledgements}

We would like to thank the staff at Crossfit Luminary in Grand Rapids, Michigan USA for their help in making this study possible. Also, special thanks to the participants who volunteered to take part in this study. There was no funding provided in support of this study. The authors have no conflicts of interest related to this research. The results of this study do not constitute endorsement of any products by the authors.

\section{References}

Baechle, T. R., \& Earle, R. W. (2008). Essentials of strength training and conditioning. (3rd Ed.). Champaign, IL: Human Kinetics.

Braidot, A. A., Brusa, M. H., Lestussi, F. E., \& Parera, G. P. (2007). Biomechanics of front and back squat exercises. Journal of Physics: Conference Series, 90(1), 012009.

Comfort, P., Pearson, S. J., \& Mather, D. (2011). An electromyographical comparison of trunk muscle activity during isometric trunk and dynamic strengthening exercises. Journal of Strength \& Conditioning Research, 25(1), $149-154$.

Contreras, B., Vigotsky, A. D., Schoenfeld, B. J., Beardsley, C., \& Cronin, J. (2016). A comparison of gluteus maximus, biceps femoris, and vastus lateralis EMG amplitude in the parallel, full, and front squat variations in resistance trained females. Journal of Applied Biomechanics, 31(1), 16-22.

Cowley, P. M., \& Swensen, T. C. (2008). Development and reliability of two core stability field tests. Journal of Strength and Conditioning Research, 22(2), 619-624.

DeBeliso, M., Sevene, T.G., Adams, K.J., Harris. C., Climstein, M., \& Berning, J.M. (2013). The effects of a back-belt on lumbar disc deformation during stoop type lifting. International Journal of Science and Engineering Investigations, 2(16), 1-10.

Durall, C. J., Greene, P. F., \& Kernozek, T. W. A. (2012). Comparison of two isometric tests of trunk flexor endurance, Journal of Strength \& Conditioning Research, 26(7), 1939-1944.

Fees, M., Decker, T., Snyder-Mackler, L., \& Axe, M. (1998). Upper extremity weight-training modifications for the injured athlete. American Journal of Sports Medicine, 26(5), 732-742.

Gullett, J. C., Tillman, M. D., Gutierrez, G. M., \& Chow, J. W. (2009). A biomechanical comparison of back and front squats in healthy trained individuals. Journal of Strength \& Conditioning Research, 23(1), 284-292.

Hamlyn, N., Behm, D. G., \& Young, W. B. (2007). Trunk muscle activation during dynamic weight-training exercises and isometric instability activities. Journal of Strength \& Conditioning Research, 21(4), 1108-1112.

Hibbs, A. E., Thompson, K. G., French, D., Wrigley, A., \& Spears, I. (2008). Optimizing performance by improving core stability and core strength. Sports Medicine, 38(12), 995-1008.

Hodges P. W., \& Richardson C. A. (1996). Inefficient muscular stabilization of the lumbar spine associated with low back pain. A motor control evaluation of transversus abdominis. Spine, 21(22), 2640-2650.

Huxel-Bliven, K. C., \& Anderson, B. E. (2013). Core stability training for injury prevention. Sports Health: A Multidisciplinary Approach, 5(6), 514-522. 
Kibler, W. B., Press, J., \& Sciascia, A. (2006). The role of core stability in athletic function. Sports Medicine, 36(3), 189-198.

Kulas, A. S., Schmitz, R. J., Shultz, S. J., Henning, J. M., \& Perrin, D. H. (2006). Sex-specific abdominal activation strategies during landing. Journal of Athletic Training, 41(4), 381-386.

Leetun, D. T., Ireland, M. L., Wilson, J. D., Ballantyne, B. T., \& Davis, I. M. (2004). Core stability measures as risk factors for lower extremity injury in athletes. Medicine \& Science in Sports \& Exercise, 36(6), 926-934.

Mayer, T., Gatchel, R., Betancur, J., \& Bovasso, E. (1995). Trunk muscle endurance measurement: isometric contrasted to isokinetic testing in normal subjects. Spine, 20(8), 920-927.

McBride, J. M., Triplett-McBride, T., Davie, A., \& Newton, R. U. (2002). The effect of heavy-vs. light-load jump squats on the development of strength, power and speed. Journal of Strength \& Conditioning Research, 16(1), 75-82.

McGill, S.M. (1998). Low back exercises: Evidence for improving exercise regimens. Physical Therapy Journal, 78(7), 754-765.

McGill, S. M., Childs, A., \& Liebenson, C. (1999). Endurance times for low back stabilization exercises: Clinical targets for testing and training from a normal database. Archives of Physical Medicine and Rehabilitation, 80(8), 941944.

McKean, M., \& Burkett, B. J. (2012). Does segment length influence the hip, knee and ankle coordination during the squat movement? Journal of Fitness Research, 1(1), 23-30.

McKean, M. R., Dunn, P. K., \& Burkett, B. J. (2010). The lumbar and sacrum movement pattern during the back squat exercise. Journal of Strength \& Conditioning Research, 24(10), 2731-2741.

McMaster, D.T, Gill, N., Cronin, J., \& McGuigan, M. (2014). A brief review of strength and ballistic assessment methodologies in sport. Sports Medicine 44(5), 603-623.

Mendiguchia, J., Ford, K. R., Quatman, C. E., Alentorn-Geli, E., \& Hewett, T. E., (2011). Sex differences in proximal control of the knee joint. Sports Medicine, 41(7), 541-557.

Nadler, S. F., Malanga, G. A., Bartoli, L. A., Feinberg, J. H., Prybicien, M., \& DePrince, M. (2002). Hip muscle imbalance and low back pain in athletes: influence of core strengthening. Medicine \& Science in Sports \& Exercise, 34(1), 9-16.

Nesser, T. W., Huxel, K. C., Tincher, J. L., \& Okada, T. (2008). The relationship between core stability and performance in division I football players. Journal of Strength \& Conditioning Research, 22(6), 1750-1754.

Nesser, T., \& Lee, W. (2009). The relationship between core strength and performance in division I female soccer players. Journal of Exercise Physiology Online, 12(2), 21-28.

Nikolenko, M., Brown, L.E., Coburn, J.W., Nikolenko, M., Spiering, B.A., \& Tran, T.T. (2011). Relationship between core power and measures of sport performance. Kinesiology, 43(2), 163-168.

O'Shea, P. (2000). Quantum Strength Fitness II (Gaining the winning edge). Applied strength training \& conditioning for winning performance, Patrick's Books, Corvallis, OR, USA.

Paine, R., \& Voight, M. L. (2013). The role of the scapula. International Journal of Sports Physical Therapy, 8(5), 617629.

Raizanda, S., \& Bagchi, A. (2015). A comparative electromyographical investigation of L1 and L5 paraspinal muscles during two variations of back and front squats. International Journal of Physical Education, Sports and Health, 2(1), 252-255.

Sadeghi, H., Shariat, A., Asadmanesh, E., \& Mosavat, M. (2013). The Effects of core stability exercise on the dynamic balance of volleyball players. International Journal of Applied Exercise Physiology, 2(2), 1-10.

Safrit, M.J., \& Wood, T.M. (1995). Introduction to measurement in physical education and exercise (3rd Ed.) St. Louis, MO: Mosby.

Sanborn, K., Boros, R., Hruby, J., Schilling, B., O’Bryant, H. S., Johnson, R. L., Hoke, T., \& Stone, M. H. (2000). Short-term performance effects of weight training with multiple sets not to failure vs. a single set to failure in women. Journal of Strength \& Conditioning Research, 14(3), 328-331.

Schoenfeld, B. J. (2010) Squatting kinematics and kinetics and their application to exercise performance. Journal of Strength \& Conditioning Research, 24(12), 3497-3506.

Shariat, A., Kargarfard, M., Danaee, M., \& Tamrin, S. B. M. (2015). Intensive resistance exercise and circadian salivary testosterone concentrations among young male recreational lifters. The Journal of Strength \& Conditioning Research, 29(1), 151-158.

Seo, D., Kim, E., Fahs, C. A., Rossow, L., Young, K., Ferguson, S. L., Thiebaud, R., Sherk, V. D., Loenneke, J. P., Kim, D., Lee, M. K., Choi, K. H., Bemben, D. A., Bemben, M. G., \& So, W. Y. (2012). Reliability of the one-repetition maximum test based on muscle group and gender. Journal of Sports Science \& Medicine, 11(2), 221-225. 
Tse, M. A., McManus, A. M., \& Masters, R. S. (2005). Development and validation of a core endurance intervention program: implications for performance in college-age rowers. The Journal of Strength \& Conditioning Research, 19(3), 547-552

Walsh, J. C., Quinlan, J. F., Stapleton, R., Fitzpatrick, D. P., \& McCormack, D. (2007). Three-dimensional motion analysis of the lumbar spine during "free squat" weight lift training. American Journal of Sports Medicine, 35(6), 927932.

Wilson, J. D., Dougherty, C. P., Ireland, M. L., \& Davis, I. M. (2005). Core stability and its relationship to lower extremity function and injury. Journal of the American Academy of Orthopaedic Surgeons, 13(5), 316-325.

Wisløff, U., Castagna, C., Helgerud, J., Jones, R., \& Hoff, J. (2004). Strong correlation of maximal squat strength with sprint performance and vertical jump height in elite soccer players. British Journal of Sports Medicine, 38(3), 285-288.

Yavuz, H. U., Erdağ D, Amca A. M., \& Aritan S. (2015) Kinematic and EMG activities during front and back squat variations in maximum loads. Journal of Sports Science, 33(10), 1058-1066.

Zeller, B. L., McCrory, J. L., Kibler, W. B., \& Uhl, T. L. (2003). Differences in kinematics and electromyographic activity between men and women during the single-legged squat. American Journal of Sports and Medicine, 31(3), 449456. 